\title{
Glaucomatous blindness in the Negev: a descriptive study of age, sex, and ethnic patterns
}

\author{
ROBERT DAVID,' YAAKOV DAN,' AND DAVID H. STONE ${ }^{2}$ \\ From the Departments of ${ }^{1}$ Ophthalmology and ${ }^{2}$ Epidemiology, Faculty of Health Sciences, \\ Ben-Gurion University of the Negev, Beer Sheva, Israel
}

SUMMARY Two sources of data (a blind register and the records of a glaucoma clinic) were used to study the age, sex, and ethnic characteristics of sufferers of glaucomatous blindness in the Negev region of Israel. Glaucoma was found to be the cause of blindness relatively infrequently (10\% of eyes) among the registered blind population. The rate of blindness from glaucoma in the population was $0 \cdot 38 / 1000$. Glaucomatous blindness affected more males than females and more individuals of Eastern and Western origin. A steep gradient of increasing number of blind with advancing age was found in both sexes and both ethnic groups, but the gradient was steeper in males and females of Eastern origin. These findings are consistent with the pattern expected of a developing country and represent the first descriptive profile of the pattern of personal characteristics of sufferers from glaucomatous blindness in this region. The ethnic pattern resembles what is known about the natural history of glaucoma in pigmented and nonpigmented races.

Glaucoma is one of the main causes of blindness throughout the world. Its natural course is insidious, and, when it is detected and properly treated at an early stage, progression to blindness can usually be arrested. ${ }^{1}$ Its relative importance as a cause of blindness varies from one country to another: it has been reported to be the second or third commonest cause of blindness in the United States ${ }^{23}$ and third in the United Kingdom, ${ }^{4}$ while in the developing countries it has been reported to rank only fifth. ${ }^{5}$

Little has been published about the causes of blindness in Israel generally or in its southern arid zone, the Negev, in particular. The present study was an attempt to assess the relative importance of glaucoma as a cause of blindness in the Negev and to establish the age, sex, and ethnic characteristics of sufferers from the condition.

\section{Materials and methods}

The definition of blindness accepted by the Israeli Ministry of Health, and by the authors of this study, is a visual acuity of $3 / 60$ or less in the better eye or a reduction in the visual field to $20^{\circ}$ or less.

Correspondence to Dr R. David, Department of Ophthalmology, Soroka Medical Center, Department of Ophthalmology, Beer Sheva, Israel.
Two independent sources of information were studied. The first was the Glaucoma Service of the Department of Ophthalmology, the Soroka Medical Centre, Beer Sheva, which serves virtually all glaucoma patients in the Negev area. For every patient there is a file containing demographic information as well as details of ophthalmological diagnosis and treatment. At the end of May 1982, when the data for this study were collected, there were 754 patients registered with the Glaucoma Clinic. Of these no blind patients were identified in the diagnostic categories of acute angle-closure glaucoma (119 patients), contusion angle-recess glaucoma (11 patients), and undefined glaucoma (24 patients). All of these cases, as well as 273 patients being followed up for ocular hypertension, were excluded. Of the remaining 329 patients 46 fulfilled the blindness criteria, and data on their age, sex, ethnic origins, and diagnosis were extracted from the records and analysed.

The second source of data was the Blind Register of the regional office of the Ministry of Works and Welfare. Of the 809 records of registered persons 139 did not contain sufficient information and hence were excluded from the study. Details of age, sex, and ethnic origin were extracted from the register, but in contrast with the clinic files the type of glaucoma was 
Table 1 Frequency of causes of registered blindness in the Negev in the 670 individuals (1340 eyes) for whom adequate records are available

\begin{tabular}{llr}
\hline Cause of blindness & No. of eyes & $\%$ \\
\hline 1. Corneal disease & 330 & $24 \cdot 6$ \\
2. Retinal and afferent pathway & & \\
disease & 252 & $18 \cdot 8$ \\
3. Retinal detachment and myopic & & \\
& 210 & $15 \cdot 7$ \\
degeneration & 196 & $14 \cdot 6$ \\
5. Phthisis and anophthalmus & 130 & $9 \cdot 7$ \\
6. Glaucoma & 127 & $9 \cdot 5$ \\
7. Diabetic retinopathy & 55 & $4 \cdot 1$ \\
8. Optic atrophy & 40 & $3 \cdot 0$ \\
Total & 1340 & $100 \cdot 0$ \\
\hline
\end{tabular}

Table 2 Distribution of type of glaucoma and frequency of blindness among the 329 glaucomatous patients under the care of the Glaucoma Clinic

\begin{tabular}{lrrrrr}
\hline \multirow{2}{*}{ Type of glaucoma } & \multicolumn{2}{c}{ Total patients } & & \multicolumn{2}{c}{ Blind patients } \\
\cline { 2 - 3 } \cline { 5 - 6 } & No. & $\%$ & & No. & $\%$ \\
\hline Open-angle & 196 & 100 & & 29 & 15 \\
Chronic angle-closure & 56 & 100 & & 6 & 11 \\
Low-tension & 11 & 100 & & 3 & 27 \\
Secondary & 50 & 100 & & 4 & 8 \\
Juvenile & 16 & 100 & & 4 & 25 \\
Total & 329 & 100 & & 46 & 14 \\
\hline
\end{tabular}

not recorded. Since the cause of blindness was not always identical in both eyes, each eye was analysed separately. Thus in this group there were 1340 eyes (for 670 persons).

\section{Results}

Table 1 shows the distribution of the causes of blindness among the 670 registered blind persons for whom sufficient data were available. Glaucoma was a relatively infrequent cause of blindness $(10 \%$ of eyes). Fifty-nine individuals had bilateral glaucoma.

The distribution of the types of glaucoma and frequency of blindness among the 329 glaucomatous patients from the glaucoma clinic is shown in Table 2. Although open-angle glaucoma was the largest single contributor to the total number of blind patients, the proportion of all open-angle glaucoma patients who were blind was only $15 \%$, in contrast with the higher proportions blind among patients with the rarer types of glaucoma such as congenital and low-tension glaucoma, where the rates of blindness $(25 \%$ and $28 \%$, respectively) were higher.

Tables 3 and 4 show the distribution of blind persons according to sex and ethnic origin. In both sources males outnumbered females, and Jews of Oriental (Sefardi) origin outnumbered Jews of Western (Ashkenazi) origin. Interestingly, females outnumbered males among the 13 Western jews attending the clinic and among the 8 Western Jews who were on the Blind Register, but the numbers are too small to draw meaningful conclusions from this.

Table 5 shows the steep age gradient in the distribution of blind persons identified by combining the 2 sources. Men appear to have become blind at a younger age than women and to have preceded women by roughly one decade.

Only 10 of the 46 blind patients identified from the glaucoma clinic appeared on the Blind Register. Adding the remaining 36 to the 59 individuals with bilateral disease identified from the Register gave a total figure of 95 persons with glaucomatous blindness. Since the total population of the Negev was estimated to be 276000 in $1980,{ }^{6}$ this represents a prevalence of glaucomatous blindness of 0.38 per 1000 .

\section{Discussion}

For the first time this study has provided baseline descriptive data on the age, sex, and ethnic characteristics of victims of glaucomatous blindness in the Negev. The relatively low ranking of glaucoma in the frequency table of causes of blindness in this study is simila: to the findings reported from developing countries, ${ }^{5}$ although comparisons are problematical because of varying definitions of blindness. The Negev population structure may account for this pattern, in that it contains a high proportion of children and younger people, as well as a larger Jewish immigrant population originating from North Africa, who present severe trachomatous sequelae contracted in their countries of origin. The ethnic composition of the patients under the care of the Glaucoma Clinic is equally divided between patients

Table 3 Ethnic origin and sex distribution of patients with glaucomatous blindness identified from the Glaucoma Clinic

\begin{tabular}{|c|c|c|c|c|c|c|c|}
\hline \multirow{2}{*}{$\begin{array}{l}\text { Ethnic } \\
\text { origin }\end{array}$} & \multicolumn{2}{|c|}{ Males } & \multicolumn{2}{|c|}{ Females } & \multirow{2}{*}{$\begin{array}{l}\text { Sex } \\
(M: F) \\
\text { ratio }\end{array}$} & \multicolumn{2}{|c|}{ Total } \\
\hline & No. & $\%$ & No. & $\%$ & & No. & $\%$ \\
\hline $\begin{array}{l}\text { Eastern } \\
\text { Western } \\
\text { Total }\end{array}$ & $\begin{array}{r}22 \\
6 \\
28\end{array}$ & $\begin{array}{l}78 \cdot 6 \\
21 \cdot 4 \\
100\end{array}$ & $\begin{array}{r}11 \\
7 \\
18\end{array}$ & $\begin{array}{c}61 \cdot 1 \\
38 \cdot 9 \\
100\end{array}$ & $\begin{array}{l}2 \cdot 0 \\
0 \cdot 9 \\
1 \cdot 6\end{array}$ & $\begin{array}{l}33 \\
13 \\
46\end{array}$ & $\begin{array}{l}71 \cdot 7 \\
28 \cdot 3 \\
100\end{array}$ \\
\hline
\end{tabular}


Table 4 Ethnic origin and sex distribution of patients with glaucomatous blindness identified from the Blind Register

\begin{tabular}{|c|c|c|c|c|c|c|c|}
\hline \multirow{2}{*}{$\begin{array}{l}\text { Ethnic } \\
\text { origin }\end{array}$} & \multicolumn{2}{|c|}{ Males } & \multicolumn{2}{|c|}{ Females } & \multirow{2}{*}{$\begin{array}{l}\text { Sex } \\
\text { (M:F) } \\
\text { ratio }\end{array}$} & \multicolumn{2}{|c|}{ Total } \\
\hline & No. & $\%$ & No. & $\%$ & & No. & $\%$ \\
\hline Eastern & 40 & $95 \cdot 2$ & 11 & $64 \cdot 7$ & $3 \cdot 6$ & 51 & $86 \cdot 4$ \\
\hline Western & 2 & $4 \cdot 8$ & 6 & $35 \cdot 3$ & $0 \cdot 3$ & 8 & $13 \cdot 6$ \\
\hline Total & 42 & 100 & 17 & 100 & $2 \cdot 5$ & 59 & 100 \\
\hline
\end{tabular}

Table 5 Age and sex specific prevalence rates of ascertained glaucomatous blindness in the Negev

\begin{tabular}{|c|c|c|c|c|c|c|}
\hline \multirow[t]{2}{*}{ Age (years) } & \multicolumn{2}{|c|}{ Males } & \multicolumn{2}{|c|}{ Females } & \multicolumn{2}{|c|}{ Total } \\
\hline & No. & Rate/1000 pop. & No. & Rate/1000 pop. & No. & Rate/1000 pop. \\
\hline $0-40$ & 4 & 0.04 & 1 & $0 \cdot 01$ & 5 & 0.03 \\
\hline $41-50$ & 3 & $0 \cdot 27$ & 2 & $0 \cdot 17$ & 5 & $0 \cdot 22$ \\
\hline $51-60$ & 13 & $1 \cdot 55$ & 5 & 0.56 & 18 & 1.04 \\
\hline $61-70$ & 14 & $2 \cdot 68$ & 8 & 1.42 & 22 & 2.03 \\
\hline $70+$ & 30 & $7 \cdot 94$ & 15 & $3 \cdot 61$ & 45 & $5 \cdot 67$ \\
\hline All ages & 64 & 0.53 & 31 & $0 \cdot 25$ & 95 & $0 \cdot 38$ \\
\hline
\end{tabular}

Chi-square: $($ males $)=156(4 \mathrm{df}) ; p<0 \cdot 001$. Chi-square: $($ females $)=84(4 \mathrm{df}) ; p<0 \cdot 001$. Yates's continuity correction applied in both cases.

of Eastern and Western origin, while the frequency of blindness is much higher among those of Eastern origin. The lack of available data on the distribution of the population of the Negev by ethnic groups makes it difficult to draw firm conclusions, but this finding suggests that the natural history of glaucoma takes a more severe course among patients of Eastern origin. Some support for this hypothesis comes from reports in the literature that glaucoma has a poorer visual prognosis in pigmented races. ${ }^{7 \rightarrow}$

The age and sex characteristics which we observed are consistent with data from elsewhere. The steep increase in glaucomatous blindness after the age of 50 is well recognised, as is the more rapid progression to blindness among males than in females. ${ }^{34}$ Our finding that the sex ratio among the Western blind (the majority of whom were female) is the reverse of that of the Eastern blind (the majority of whom were male) is difficult to interpret because of the small numbers.

The fact that 36 blind patients in the Glaucoma Clinic were not on the Blind Register is not surprising in view of the findings of other authors that up to $50 \%$ of blind people may not be registered. ${ }^{1011}$ The observation that $90 \%$ of the registered blind in the present study were of Eastern origin probably reflects behavioural rather than biological differences.

Finally, it is noteworthy that 30 of the 46 blind patients under the care of the glaucoma clinic had undergone, at some stage, pressure-lowering surgery in an attempt to arrest the downhill course of the disease. This inability to control some glaucoma cases has been acknowledged previously ${ }^{12}$ and should always be borne in mind by the practising ophthalmologist.

This study was partly supported by the Middle East Eye Research Institute, Ben-Gurion University of the Negev, Beer Sheva, Israel.

\section{References}

1 Scheie HG, Albert DM. Glaucoma. In: Scheie HG, Albert DM, eds. Adler's textbook of medicine. 8th ed. Philadelphia: Saunders, 1969: 336.

2 Bellows JG. Glaucoma: a cause of needless blindness. JSC Med Assc 1977; 73: 70-1.

3 Hiller R, Kahn HA. Blindness from glaucoma. Am J Ophthalmol 1975; 80: 62-9.

4 Sorsby A. The incidence and causes of blindness in England and Wales 1963-68. (Report on Public Health and Medical Subjects No. 128). London: HMSO, 1972: 11-3.

5 Wilson J, ed. World blindness and its prevention. New York: Oxford University Press, 1980.

6 Statistical Abstract of Israel 1982, No. 33. Jerusalem: Central Bureau of Statistics, 1982: 40.

7 Luntz MH. Primary angle closure glaucoma in urbanized South African caucasoid and negroid communities. $\mathrm{Br} J$ Ophthalmol 1973; 57: 445-56.

8 Harris LS, Galin MA. Effect of ocular pigmentation on hypotensive response to pilocarpine. Am J Ophthalmol 1971; 72: 923-5.

9 Melikian HE, Lieberman TW, Leopold IH. Ocular pigmentation and pressure and outflow responses to pilocarpine and epirephrine. Am J Ophthalmol 1971; 72: 70-8.

10 Josephson E. Problems in studying blind people. In: Proceedings of the Third Annual Conference of the Model Reporting Area for Blindness Statistics. Washington: US Department of HEW, 1964: 45-50.

11 Graham PA, Wallace J, Welsby E, Grace HJ. Evaluation of postal detection of registrable blindness. Br J Prev Soc Med 1968; 22: $238-41$.

12 Leske ML, Rosenthal J. Epidemiologic aspects of open angle glaucoma. Am J Epidemiol 1979; 109: 250-72. 